To date, most trials of the effectiveness of acetylcholinesterase inhibitors in dementia have followed patients for a minimum of six months. But no one yet knows how quickly an alteration in acetylcholine concentrations might result in a measurable restoration of memory. And, to achieve optimal benefits, it may also prove necessary to offer a period of "retraining" to reorient the brain, in addition to improving the neurotransmitter concentrations.
It remains to be seen how well these drugs actually work in Alzheimer's disease. In future it may be shown that other types of dementia with less complex pathological processes may be more responsive. One example is the dementia associated with Lewy bodies in which the pathological process does not also include the presence of amyloid or tangles to the same extent as in Alzheimer's disease.

Abi Berger Science editor, BMJ

\title{
Patients' and doctors' attitudes to amount of information given after unintended injury during treatment: cross sectional, questionnaire survey
}

\author{
Melanie Hingorani, Tina Wong, Gilli Vafidis
}

Central Eye Unit, Central Middlesex Hospital, London NW10 7NS

Melanie Hingorani, specialist registrar

Tina Wong, senior house officer Gilli Vafidis, consultant

Correspondence to: Mrs Hingorani

BMJ 1999;318:640-
Unintended injuries (adverse events) caused during treatment are much more common than previously believed. ${ }^{1}$ Recent legal and disciplinary cases have shown that, although patients are increasingly dissatisfied with a perceived lack of openness in the medical profession, doctors are not legally obliged to provide an explanation after an adverse event. ${ }^{2}$ Because of this, the General Medical Council has revised its guidance on good medical practice, stating that after an adverse event a full and honest explanation and an apology should be provided routinely. ${ }^{3}$ We surveyed patients' and doctors' attitudes to the provision of information to patients after a hypothetical adverse event in cataract surgery.

\section{Subjects, methods, and results}

A specifically designed questionnaire (box) was used to survey all patients attending a consultant ophthalmologist's clinic during five weeks in 1998; 246 of 302 (81\%) patients agreed to participate. All 48 ophthalmologists attending a regional meeting also participated. The questionnaire asked about the postoperative information that should be given routinely in a hypothetical situation in which a common intraoperative complication (posterior capsular rupture) occurred in cataract surgery, with an estimated 10\% risk of an adverse effect on vision.

The attitudes of the patients differed substantially from those of the ophthalmologists: $226(92 \%)$ patients, compared with only $29 \quad(60 \%)$ ophthalmologists, believed that a patient should always be told if a compli-

\section{Questionnaire}

Please read the following story (which is typical but fictional)

Mrs Brown has an operation for cataract. During surgery, there is a complication. The lens capsule breaks and the surgeon has to make a bigger cut than planned, use stitches and put in a different style of lens implant. There is approximately $a 1$ in 10 chance of her vision being affected by these changes.

The next day, she sees well and is pleased.

Should Mrs Brown be told about the surgical problem? Yes / No

If yes, do we discuss the possible consequences? Yes / Only if she asks / No Please comment on your decision overleaf.

What is your age? 25 and under / 26-60 years / over 60 years cation has occurred $\left(\chi^{2}=34.5,1 \mathrm{df}, \mathrm{P}<0.001\right.$; odds ratio $7.4(95 \%$ confidence interval 3.7 to 14.3$))$. The ophthalmologists who did not believe that patients should always be told replied that either the patient should never be told or that it depended on the circumstances. Two hundred (81\%) patients, but only $16(33 \%)$ ophthalmologists, believed that a patient should not only be informed of a complication but also be given detailed information on possible adverse outcomes $\left(\chi^{2}=47.1\right.$, $1 \mathrm{df}, \mathrm{P}<0.001 ; 8.7$ (4.7 to 15.9$)$ ).

\section{Comment}

Our survey shows that after an adverse event patients expect more detailed information than doctors believe should be given. Doctors' reluctance to provide detailed information to patients after adverse events is often an attempt to protect the patient from potentially detrimental anxiety. However, doctors may also avoid telling patients because it is a time consuming, difficult, and unpleasant task and because they fear losing a patient's trust, being blamed, and perhaps sued. In addition, it has been suggested that the current medical culture, in which error is often automatically equated with professional incompetence or inadequacy, makes admission to either patients or colleagues difficult. ${ }^{4}$ Many studies show, however, that failure to provide information, an explanation, and an apology increases the risk of litigation and erodes the patient-doctor relationship. ${ }^{5}$ After an adverse event, patients want disclosure of the event, admission of responsibility, an explanation, an apology, and prevention of future similar errors; in some cases, they also want the offender to be punished and to obtain financial compensation. ${ }^{5}$

The practice of medicine can never be free of errors, ${ }^{4}$ and changes are required in the attitudes of both patients and the medical profession, with realistic expectations of the limitations of doctors and medicine and greater, blame free openness. In the light of the new regulations from the General Medical Council, failure to acknowledge an adverse event arising during treatment may now have serious professional consequences for a practitioner.

We thank Mr Jeremy Joseph for his advice. 
Contributors: The original idea for the study arose jointly in a meeting of the three authors. GV and $\mathrm{MH}$ designed and piloted the questionnaire, and all three authors collected data and jointly wrote the paper. $\mathrm{MH}$ performed the statistical analysis. $\mathrm{MH}$ acts as the guarantor of the paper.

Funding: None.

Competing interests: None declared. al. Results of the Harvard medical practice study I. Incidence of adverse events and negligence in hospitalized patients. $N$ Engl $J$ Med 1991;324:370-6.

2 Laurance J. Doctors warned on care of patients. Independent 1998 May 20:5.

General Medical Council. Good medical practice. London: GMC, 1998.

4 Leape L. Error in medicine. JAMA 1994;272:1851-7.

5 Vincent C, Young M, Phillips A. Why do people sue doctors? A study of patients and relatives taking legal action. Lancet 1994;343:1609-13.

(Accepted 10 December 1998)
Evidence exists that cervical smears are rarely offered to women with learning disability. ${ }^{1}$ We examined whether women with learning disability were being offered and were accepting screening.

\section{Methods and results}

All residents with learning disability in one English health district who were known to health or social services were identified from the computer records of the local community health services trust and the social services department. Records were adjusted for double counting, and women eligible for cervical screening were defined as all women aged 20-64 years.

Screening histories were checked against the records of the cervical cancer screening programme. To preserve confidentiality the data collection manager who checked the records was blind to the nature of the population under study. The proportion of eligible women screened was compared with available data for the whole district.

The local ethics committee advised that the study, which was part of an audit programme, did not require ethical approval provided that nothing was to be done to the people concerned and adequate steps were taken to ensure that confidentiality was maintained.

In all, 389 of the 461 women (age range 18-94 years) identified in the overall sample of 969 residents (giving a district prevalence of learning disability of 2.2 per 1000) were eligible for cervical screening.

Forty nine (13\% (95\% confidence interval $9 \%$ to $16 \%)$ ) of the eligible women had a record of a smear test in the previous five years. Two (4\%) had inadequate smear tests, and one had follow up of a previously abnormal test. No significant differences in mean age were seen between women screened and those not screened (40.4 years $v 37.4$ years). Coverage in women with learning disability was markedly lower than for the general district population (which was 88\% in 1992-32).

\section{Comment}

The sample population of residents with learning disability probably did not include the entire district population with learning disabilities; prevalence was lower than expected (2.5 to 4 per 1000 population) and may have included people without learning disability who are in contact with those services-for example, people with brain injury acquired in adolescence).
However, such misclassification is unlikely to account for the results.

Coverage in the cervical cancer screening programme is markedly lower for women with learning disability than for the general female population. We were not able to make appropriate exclusions on the grounds of hysterectomy, although the number to whom this would apply is probably small. It is difficult to say whether the poorer coverage in women with learning disability is inequitable or reasonable as little is known about the incidence of cervical cancer in this population group. In the general female population cervical cancer is clearly related to sexual activity. Assumptions, however, that people with learning disability are sexually inactive may be wrong. ${ }^{34}$ Moreover, although the incidence of cervical cancer is extremely low in women who have never been sexually active, we believe that such women should still be invited for screening-if only to record the grounds on which they have been excluded from the screening programme.

Additional factors that may contribute to limited access and may be amenable to change include low demand for screening from women with learning disability; perceived difficulty in obtaining consent for screening $^{5}$; difficulties with using appointment systems and waiting rooms; uncertainty about whether general practitioners or specialist teams are responsible for routine care; poor liaison with specialist services; inadequate training of general practitioners in communication skills; pressure of competing demands from other groups of patients.

Further research is needed into the effectiveness and efficiency of screening and, perhaps most importantly, into acceptability of screening by women with learning disabilities.

Contributors: KS and NA designed the study after an original idea by NA. KS carried out data collection and analysis. Both authors drafted the final manuscript. KS is the guarantor for the paper.

Funding: No special funding.

Competing interests: None declared.

Royal College of General Practitioners. Primary care for people with mental handicap. London: RCGP, 1990. (Occasional paper 47.)

2 Allen N. Annual report of the director of public health. Southampton: Southampton and South West Hants Health Commission, 1994.

3 Reid DA. Sexual activity in people with profound learning disabilities. $B$ J Learning Disability 1995;23:56-8.

Beail N, Warden S. Sexual abuse of adults with learning disabilities. Journal of Intellectual Disability Research 1995;39:382-7.

5 Haire A, Bambrick M, Jones J. Cervical screening for women with a mental handicap. Br J Fam Planning 1992;17:120-1.

(Accepted 10 December 1998)
Southampton and South West Hants Health Authority Southampton SO16 4GX

Ken Stein, senior registrar Nick Allen, director of health strategy and public health

Correspondence to: Dr K Stein, Wessex Institute for Health Research and Development, Boldrewood, University of

Southampton, Highfield, Southampton SO15 2GS

BMJ 1999;318:641 